\title{
Strategic Cost Management Models
}

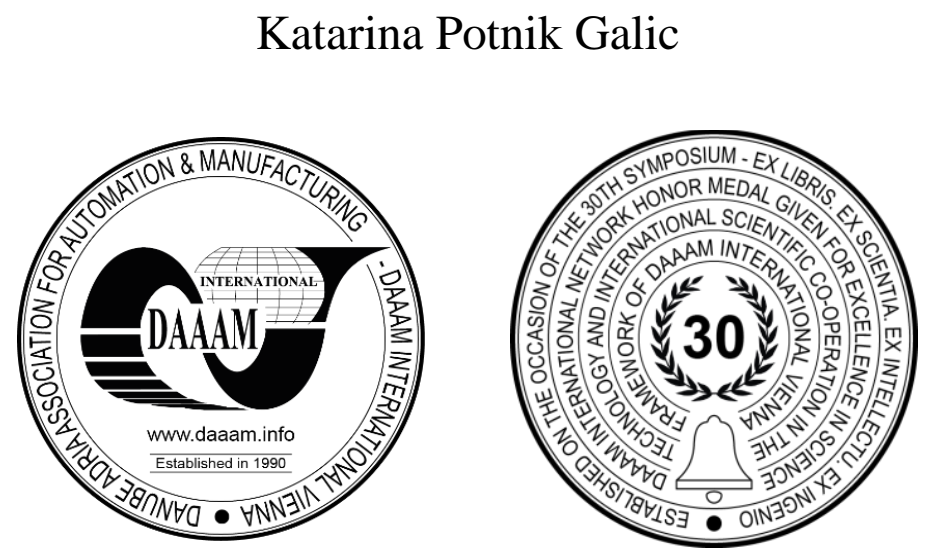

This Publication has to be referred as: Potnik Galic, K[atarina] (2020). Strategic Cost Management Models, Proceedings of the 31st DAAAM International Symposium, pp.0950-0955, B. Katalinic (Ed.), Published by DAAAM International, ISBN 978-3-902734-29-7, ISSN 1726-9679, Vienna, Austria

DOI: $10.2507 / 31$ st.daaam.proceedings. 132

\begin{abstract}
Strategic cost management is a significant area of research in current business conditions. Identifying key cost drivers can help companies focus on essential activities in the business process. That implies that the organization needs to implement an appropriate strategic cost management framework to reduce costs in key areas on which its business success depends. The aim of this paper is to analyse the instruments and propose a model of strategic cost management with the aim of more realistic presentation of the amount of costs and achieving more efficient and effective operations.
\end{abstract}

Keywords: Strategic Cost Management Models

\section{Introduction}

Strategic cost management includes applying those cost management techniques that affect cost reduction while improving the company's strategic position. It most often refers to the use of information obtained by modern costing to support the company's strategic goals. Namely, the data provided by modern cost management methods have the most crucial role in determining strategic management guidelines. They provide managers information on the structure and behaviour of costs and thus allow the company to improve its strategic competitive advantages.

With constant changes in the business environment and more dynamic business conditions, the need for comprehensive decision-making systems that the traditional cost management model cannot meet (due to the short-term nature of the information it provides) has become more and more affirmed. Namely, traditional cost management systems were developed when direct labour cost had a large share of the total cost. Changes in production technologies, such as "just in time" philosophy, robotics, and flexible production systems, have reduced direct labour costs and increased overhead costs. For this reason, modern costing methods, which allocate overheads to products based on activities, have a higher degree of objectivity in the allocation of overheads to products compared to traditional methods. Over time, awareness of the importance of building and implementing modern cost management techniques has grown, driven by the fact that the greatest impact on the competitive power of companies have information that is the product of modern cost management methods.

As a result of all the above, various techniques of modern cost management have been developed, the most important of which are: 
- Activity-Based Costing - ABC,

- Target Costing - TC,

- Life Cycle Costing - LCC,

- Value Analysis - VA,

- Quality costing,

- Kaizen Costing.

In the field of strategic cost management, there are many publications, especially scientific papers that address the topic of "ABC" methods and methods of target costing. A significantly smaller number of publications are from life cycle cost analysis, especially in the analysis which valorises costs in the products' life cycle. Therefore, there is a need for additional scientific research to adopt models for more straightforward implementation of modern cost management models in business, which would contribute to encouraging the application of these cost management methods in Croatian companies.

This paper aims to analyse strategic cost management methods and instruments and propose models and mechanisms for strategic cost management in order to realistically show the amount of costs and thus affect the more efficient and effective operations. The paper's expected scientific contribution can be seen through a critical assessment of current models and research results in the field of application of modern cost management methods and the development of scientific thought on the concept of strategic cost management. The research uses the simulation and comparison method, the inductive method, the generalization method, and the compilation method.

\section{Disadvantages of the traditional cost management model}

The traditional cost management model is also called the "traditional calculation method" and is the oldest cost management model. This model's main advantage is the simplicity of its application. Nowadays, it is most often used by business entities operating in a relatively stable business environment, in smaller companies, and when significant accuracy in the distribution of overhead production costs is not required. Traditional cost management methods are only calculation methods, and the information they provide is short-term.

A characteristic of the traditional costing system is that precisely determined direct production costs are added to indirect costs, usually allocated according to the costs or hours of direct labour of people and machines. In contrast, the costs of all other activities are not allocated at all, and they are considered fixed concerning production volume. Product costs determined traditionally are harmonized with financial reporting standards, and they are adjusted for external reporting. On the other hand, if this information is used in the internal reporting process, it can lead to erroneous decisions because information of costs obtained by traditional calculation methods is often inaccurate and unrealistic. The inadequacy of the application of traditional cost management models in today's business conditions refers to the following:

- the problem of accurately determining the amount of overhead costs,

- problems in allocating overheads to cost objects,

- the choice of the method by which overhead costs are allocated to cost objects,

- estimating direct operating hours and/or operating hours of the machine to calculate the overhead cost transmission rate,

- how administrative, sales, and distribution costs are handled. [1]

Thanks to the automation of production processes, the cost structure of the production sectors of developed countries are dominated by overhead production costs that cannot be directly allocated to the products that caused them. Due to this fact, the production sectors of developed countries did not match the existing accounting methods.

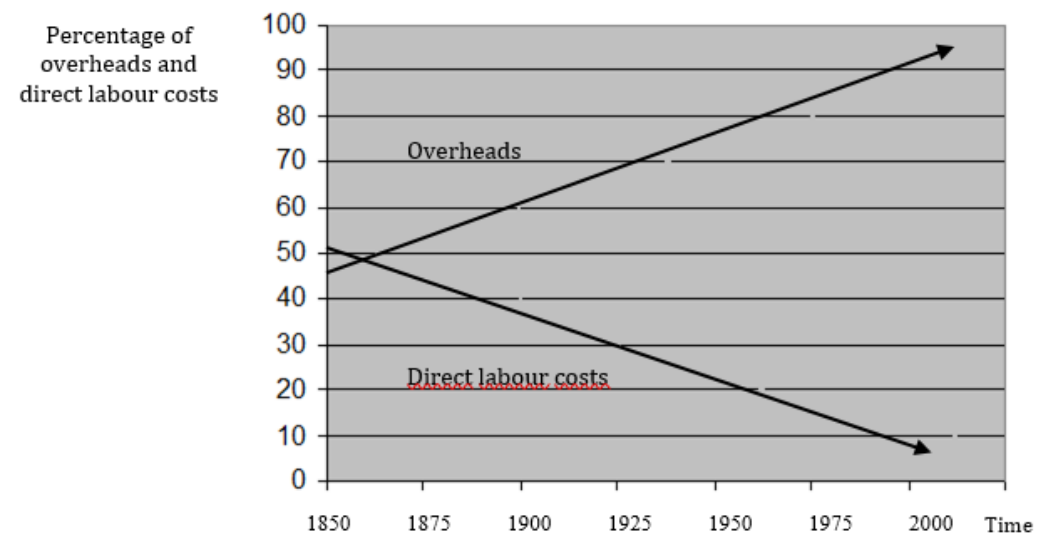

Fig. 1. The relative importance of direct labour and overheads over 150 years [12] 
They encouraged the development of new techniques and improved existing ones according to the newly created conditions to allocate costs and determine product profitability as objectively as possible. [7] Turney [12] cites an increase in overhead costs and a reduction in direct labour costs over the last 150 years as the main reason for the inadequacy of existing cost management methods.

Figure 1. shows the relative reduction of direct labour costs and the increase of overhead costs in the structure of total costs over the last 150 years, from which it can be concluded that the importance of proper allocation of overhead costs to products is growing. It is necessary to apply strategic cost management instruments in modern business conditions to ensure a correct product profitability assessment and based on such relevant information to enable strategic decisions for the company's operations. The characteristics of traditional costing methods are:

- many costs objects,

- strong focus on the production phase,

- overhead costs occupy a significant place in the calculation of the cost price,

- neglect of the strategic aspect of a business.

On the other hand, modern production is characterized by the application of modern technologies, which allow greater flexibility of products and management processes. The application of new technologies has influenced the change in the structure and character of costs. Thus, traditionally considered variable labour costs are now deemed fixed costs because it is uncertain what the production level will be in modern business conditions.

Furthermore, the classification of costs into direct and indirect costs is no longer relevant in current business conditions. Starting from the fact that the product is the leading cause of costs, calculating costs, and determining the product's price is no longer adequate. Also, some costs should belong to the entire production facility because there is no exact cause-and-effect relationship for allocating costs to products, so any type of cost allocation could distort the picture of the amount of costs of an individual product.

\section{Definition and development of strategic cost management}

Strategic cost management begins to develop with the development of management and its functions and develops scientific cost research methods. Most of the cost management techniques that are still applied today, set at the beginning of the last century. Namely, the traditional cost management system was designed in the 1870s and developed until the 1920s. However, today's dynamic business conditions are significantly different from those of the last century. Therefore, it was necessary to adapt cost management techniques to such business conditions. The business environment in which economic entities operated in the 1920s required changes in the concept of cost management and the development of modern methods of their management and accounting. Changes in the business of economic entities and the business environment lead to increased diversification of all company activities, primarily production. The modern business environment requires a quality presentation of information about organizational activities, processes, products, and users.

Modern cost management methods first developed in large companies' work processes and then became the subject of scientific and professional research by many authors. They have developed in response to all the shortcomings of the traditional cost management system because the application of each individual method of strategic cost management can contribute to eliminating these shortcomings. The term "strategic cost management" is not formally unambiguously defined but refers to combining the company's business strategy and the cost systems applied in the company. Strategic cost management in the literature is defined in different ways. Cooper and Slagmulder [4] argue that strategic cost management involves "applying different cost management techniques to improve a company's strategic position and reduce costs".

According to Horvath and Brokemper [6], strategic cost management has been developed as a key element in achieving and maintaining strategic competitive advantage through long-term forecasting and determining cost levels, cost structures, and product, process, and resource cost behaviour planning.

\section{Comparative analysis of strategic and traditional cost management model}

The new business conditions that emerged after the transition process, which primarily relate to strengthening competitiveness and adapting the business to the company's strategic needs, have resulted in the adoption of modern methods of cost management. The main disadvantage of traditional costing models is the inability to adapt the information needs to a modern company's management. In current business conditions, most of the product costs can be estimated at the design stage, and the application of traditional costing methods, which are oriented only to the production phase, while ignoring the costs incurred in other phases of the product life cycle (pre-production and post-production), leads to inefficiencies in calculating the costs caused by a particular product.

That is because traditional cost management is historically and internally oriented, focused on a specific shorter period. Also, the information generated from the traditional cost management system does not direct management's attention to those business areas where the loss occurs and results in the omission of savings opportunities. Besides, traditional cost management systems neglect individual cost drivers such as customers and suppliers. 
By applying modern methods, strategic cost management can be viewed as a response to traditional methods to achieve relevant cost information and focus on issues of strategic importance in decision-making and achieving long-term effectiveness. Predicting future events is a complex and uncertain process that requires the application of complex strategic cost management methods, and the results and information obtained by modern cost management methods could be viewed in response to the main shortcomings of traditional cost management systems. Namely, significant changes in the way production is organized and managed have significantly hampered the processes of planning, management, analysis, and cost control. The reason for that is changing in the structure of production costs due to the intensive application of modern technologies that cause an increasing reduction in direct labour costs and increase the share of overhead costs in the structure of total product costs.

Current business conditions and globalization have also influenced the strengthening of competition and the reduction of market prices. Customers are becoming more demanding, which forces companies to innovate products and services continuously. This business environment has resulted in a shorter product life cycle and faster obsolescence of technology that requires constant investment in research and development, product design, and these investments, after activation, are generally treated as overheads. Strategic cost management is not limited to the application of cost management techniques, but also other actions and tools that reduce costs and, at the same time, improve the strategic position of the company. The differences between traditional and strategic cost management concerning the various business factors they influence are shown in Table 1.

\begin{tabular}{|c|c|c|}
\hline & $\begin{array}{c}\text { Traditional cost } \\
\text { management system }\end{array}$ & $\begin{array}{c}\text { Strategic cost } \\
\text { management system }\end{array}$ \\
\hline DIRECTION & internally & externally \\
\hline GOALS & short-term, specific & $\begin{array}{l}\text { long-term for the continuous } \\
\text { realization of competitive advantages }\end{array}$ \\
\hline SCOPE & narrow & wide \\
\hline MATURITY & short term & long term \\
\hline FREQUENCY & periodically & continuously \\
\hline GOAL & value-added & the whole value chain \\
\hline ORGANIZATION & functional orientation & process orientation \\
\hline KEY DISCIPLINES & finance, accounting & marketing, economics \\
\hline
\end{tabular}

Table 1. Differences between traditional and strategic cost management [11]

The traditional approach to cost reduction has a short-term internal focus, with the primary goal of determining products and services' cost. This approach is also reactive because it does not identify the causes of costs (activities), which cause an additional cost. In contrast, strategic cost management, which involves applying modern cost management methods, is focused on the future, the external business environment, and the company's position concerning competitors in the context of decision-making for a more extended period.

From all the above, it can be concluded that current business conditions have indicated the need for a different concept of cost management because traditional models have proven to be inadequate in the newly created business environment. This inadequacy makes it difficult to make relevant decisions in economic entities' business, which relate to the purchase of equipment, pricing, resource allocation, and other business decisions. Therefore, strategic cost management, mainly its segment associated with applying these modern cost management methods, promotes the need to revitalize management accounting by extending cost estimation throughout the product life cycle.

The advantages of applying modern cost management methods compared to the traditional model are indisputable. However, the problem is the fact that these methods are mostly used separately. The individual application of strategic cost management techniques has shown major shortcomings in the calculation of total product costs and the need for a comprehensive decision-making system that would integrate as many of these techniques, from the aspect of product life cycle costing, is increasingly affirmed. [8]

Previous research [2], [3], [10] has shown that integrated cost management systems can more easily and accurately estimate actual costs, identify cost drivers and find ways to reduce total costs through product redesign or changes in product development, production and sales. 
Aware of the fact that target cost methods and value analysis, which are based on the standard costs of product components, take into account only direct costs in the calculation while ignoring overall costs, the question arises of the reality of estimating the total costs of a product. Also, the estimated cost of the product life is not based on information obtained using strategic cost management techniques. The application of an integrated cost management system eliminates these shortcomings. The following figure shows the possibilities of integrating modern cost management methods in individual phases of the product life cycle.

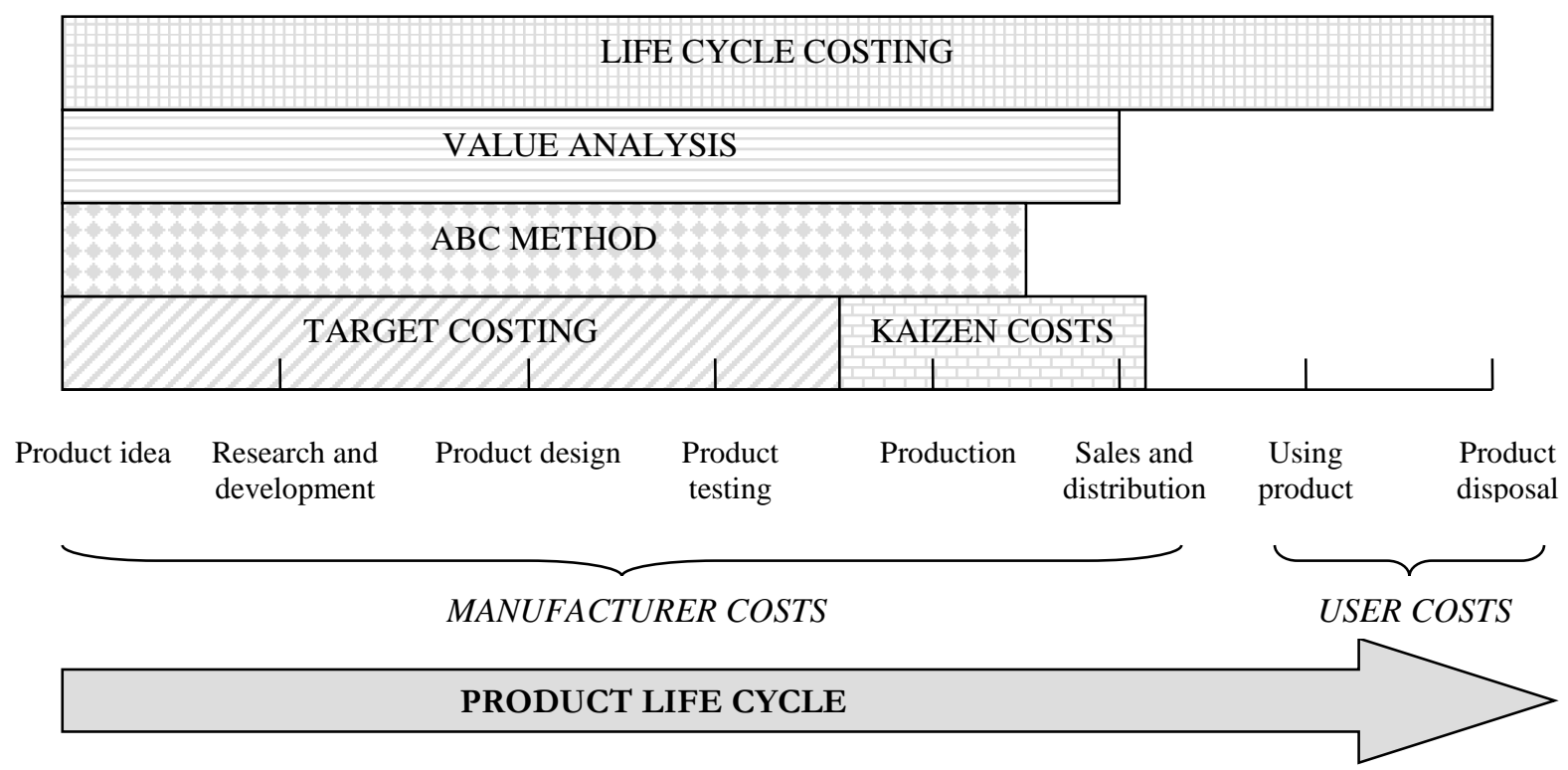

Fig. 2. Possibilities of application of modern cost management methods in the product life cycle [9]

The simplified methodology of calculating total costs within the integrated model is based on estimating costs in individual phases of the product life cycle by applying modern cost management methods. The previous figure clearly shows that all individual cost management methods, except the kaizen method, are applied from the beginning of the product idea before the product research and development phase. The Kaizen method can be applied only in the production phase because it is based on comparing actual data on the company's business with the desired and planned. Until the production stage, the target cost method and value analysis identify product components and activities to optimize costs. The kaizen method determines how much it is necessary to reduce or increase costs by individual components or activities. In this context, the $\mathrm{ABC}$ method is used to allocate overheads to products and serves as a starting point for calculating target costs. Throughout the entire process of implementing an integrated cost management system, the optimization of the amount of quality costs is implied. Based on the data prepared in this way on the amount of costs of individual activities of the entire business process, the costs of product life are calculated, especially the costs borne by the manufacturer and the costs that burden the user of the product.

The methodology of calculating the total costs of a particular product within the integrated model assumes that individual cost management methods will be used in the initial component cost estimation phase. They are direct costs where the integration of the ABC method, target cost method, and value analysis does not affect. By including overhead costs of products in the integrated model, to assess the possibilities of their reduction, it is necessary to integrate strategic cost management instruments to chronologically use the information obtained by the previously applied strategic cost management technique.

There are certain limitations to the application of this model, and they are as follows:

- lack of knowledge about modern cost management methods,

- ignorance of the company's cost structure,

- the complexity of applying modern cost management methods,

- insufficient information about the company's management on the possibilities and advantages of implementing modern cost management methods,

- insufficient or inadequate information and computer support.

Many factors need to be considered before the company's management decides to initiate changes in introducing, developing, and applying modern cost management methods. The introduction of modern cost management methods must be ensured by the existence of a strategy for the implementation of these methods. Namely, the implementation of modern cost management methods in business must be well designed and planned and supported by employees and management. 


\section{Conclusion}

Traditional cost management models have been used successfully in stable business conditions. However, developing new products and information technologies, developing awareness of consumer requirements and focusing on the customer, the growth of markets worldwide, and introducing new forms of business management have influenced the need to create a more optimal cost management model. The need for timely, relevant, and reliable information has influenced the development of modern cost management methods.

According to everything stated so far in the paper, it can be concluded that the concept of strategic cost management has a broad focus. It is not limited to continuous cost reduction and cost control but is more focused on using cost information by management relevant to decision making. Therefore, strategic cost management as a philosophy of optimal cost and revenue management is a proactive attitude and a set of techniques that improve the company's strategic position. Its application should be a prerequisite for obtaining quality and reliable cost information, and as such, it becomes one of the critical instruments of management accounting practice. In this context, it is recommended that businesses expand the scope of financial statements by including all relevant information for making strategic decisions such as information on the possibilities of reducing the time required to produce a unit of product, information on the opportunities of reducing waste in production and product quality indicators. In addition to the information already mentioned, the expanded financial statements should include statistical measures to determine the value of the variables of strategic factors of business performance.

Application of integrated cost management model ensures cost reduction and a more realistic assessment of future costs and thus product profitability in addition to the impact on the amount of costs and the assessment of the justification of product redesign, the significant role of integrated cost management systems in continuously encouraging creative and innovative activities within the company that enables management to maintain and improve the company's market position.

Further research should go in the direction of studying the intensity of application and possibilities of implementing modern cost management methods in business entities in the Republic of Croatia in order to analyse the current situation and opportunities for more efficient operations through their implementation. Further research should also be directed towards studying the possibilities of applying integrated cost management systems in industrial enterprises.

\section{References}

[1] Chadwick, L. (2000). Fundamentals of management accounting, Mate, Zagreb

[2] Cokins, G. (2002) Integrating Target Costing and ABC. Journal of Cost Management, Vol.16, No.4

[3] Cooper, R. \& Kaplan, R. (1998). Cost and Effect: Using Integrated Cost Systems to Drive Profitability and Performance. Harvard Business School Press, Boston, MA

[4] Cooper, R. \& Slagmulder, R. (1998). Achieving Full-Cycle Cost Management. MIT Sloan Management Review, Vol.46, Issue 1, pp. 45-52.

[5] Hill, C. \& Jones, G. (2001). Strategic Management Theory: An Integrated Approach. 5th ed., Houghton Mifflin Company, New York

[6] Horvath, P. \& Brokemper, A. (1998). Strategic cost management: The basis for the cost of information in the strategic planning process. Zeitschrift fur Betriebswirtschaft, June, Vol.68, Issue 6.

[7] Perčević, H. (2006). Cost calculation methods in the production sector of the Republic of Croatia, Economic Review, Croatian Society of Economists, no. 9-10 / 2006, Zagreb, UDC 657.474 (497.5), pp. 647-667.

[8] Potnik Galić, K. (2010). Possibilities of implementing an integrated cost management system, Proceedings of the 2 st. International Conference "Valis Aurea": Focus on regional development, Pozega, Croatia, ISBN 978-953-774406-9, ISBN 978-3-901509-76-6. Katalinić, B. (Ed.) pp. 1159-1163, DAAAM International Viena Austria \& Polytechnic of Pozega, Pozega.

[9] Potnik Galić, K. (2015). Strategic cost management, application of modern cost management methods, Polytechnic of Pozega, Pozega

[10] Sakurai, M. (2010). Integrated Cost Management: A Companywide Prescription for Higher Profits and Lower Costs. Productivity Press, Portland, Oregon.

[11] Shank, J. \& Govindarajan, V. (1993). Strategic Cost Management: The New Tool for Competitive Advantage. The Free Press, New York, pp. 217.

[12] Turney, P. (1996). Activity-Based Costing: The Performance Breakthrough. Kogan Page Limited, London 